\title{
Coulisses
}

Revue de théâtre

\section{Le projecteur... etc. est réparé. Sketchs de Karl Valentin - Théâtre universitaire de Liège.}

Rédaction

\section{(2) OpenEdition}

\section{Journals}

Édition électronique

URL : http://journals.openedition.org/coulisses/1648

DOI : $10.4000 /$ coulisses. 1648

ISSN : 2546-9460

Éditeur

Presses universitaires de Franche-Comté

\section{Édition imprimée}

Date de publication : 1 février 1991

Pagination : 53

ISSN : 1150-594X

\section{Référence électronique}

Rédaction, «Le projecteur... etc. est réparé. Sketchs de Karl Valentin - Théâtre universitaire de Liège. »,

Coulisses [En ligne], 3 | Hiver 1991, mis en ligne le 04 juillet 2017, consulté le 21 octobre 2019. URL

http://journals.openedition.org/coulisses/1648; DOI : 10.4000/coulisses.1648

Ce document a été généré automatiquement le 21 octobre 2019.

Coulisses 


\section{Le projecteur... etc. est réparé. Sketchs de Karl Valentin - Théâtre universitaire de Liège.}

Rédaction

Le mur séparant public et interprètes tombe... dans la bonne humeur.

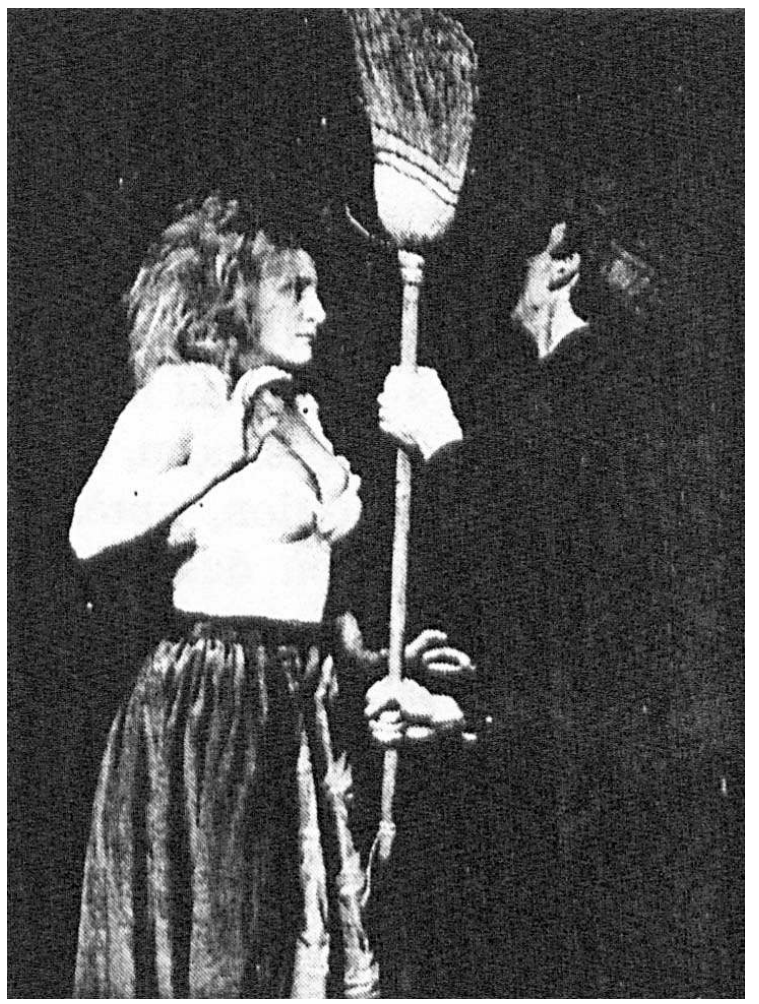




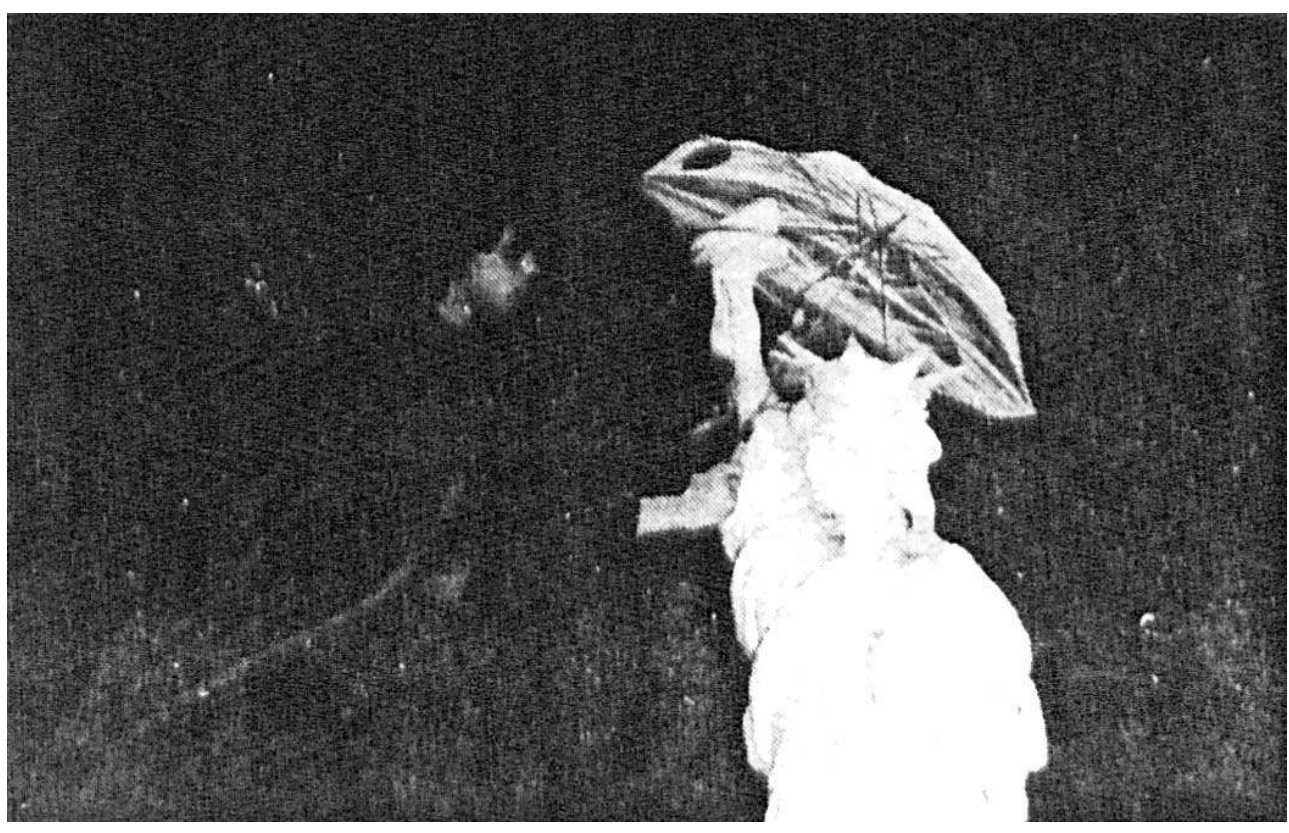

2 Le titre de ce collage de sketchs de Karl Valentin, cabarettiste du début du siècle, donne le ton de la pièce, dont le fil conducteur est le théâtre.

3 La représentation commence : c'est l'avant-spectacle, effervescence lors de laquelle les techniciens mettent en place décors et éclairages... mais le drame éclate : un projecteur est en panne... Impossible de jouer sur une scène sombre.

Pas de commencement... pas de fin...

5 Tout ce que, d'ordinaire, le public ne voit, ni n'entend jamais, lui est alors révélé.

6 Et la comédienne, capricieuse, s'impatiente...

7 Tout s'articule autour du seul problème de la panne du projecteur... problème de Théâtre... qui n'en n'est pas un... mise en scène, comédiens et décors, tout ce que l'on voit d'ordinaire, sont plongés dans l'obscurité... pas de salut! Les acteurs s'asseoient parmi les spectateurs et attendent, comme eux, le début du spectacle.

8 Déroutant... mais non sans intérêt. L'idée ne serait-elle pas de rendre le théâtre obligatoire?

9 La présence des comédiens dans le public permute les rôles de chacun. L'acteur devient spectateur, et, puisqu'il occupe la même place, le spectateur appartient désormais au jeu... La barrière qui d'habitude délimite la frontière entre acteurs et observateurs, tombe, pour laisser place à un ensemble de spectateurs, qui sont aussi acteurs, et viceversa.

$10 \mathrm{Au}$ TU de Liège, on a avant tout, pris le parti de s'amuser... aucun doute, ce type de travail y est prisé et les spectacles tournent bien souvent autour d'une réflexion sur le théâtre, notion à partir de laquelle le répertoire est choisi. Parmi les spectacles actuels, trois n'offrent pas le traditionnel salut en fin de représentation.

11 On cherche, et l'on met en scène, la frontière entre théâtre et réalité: le premier rejoint la seconde et réciproquement, lorsque la connection entre acteur et spectateur est établie... instant que privilégient la réflexion et le travail du Théâtre universitaire de Liège. 